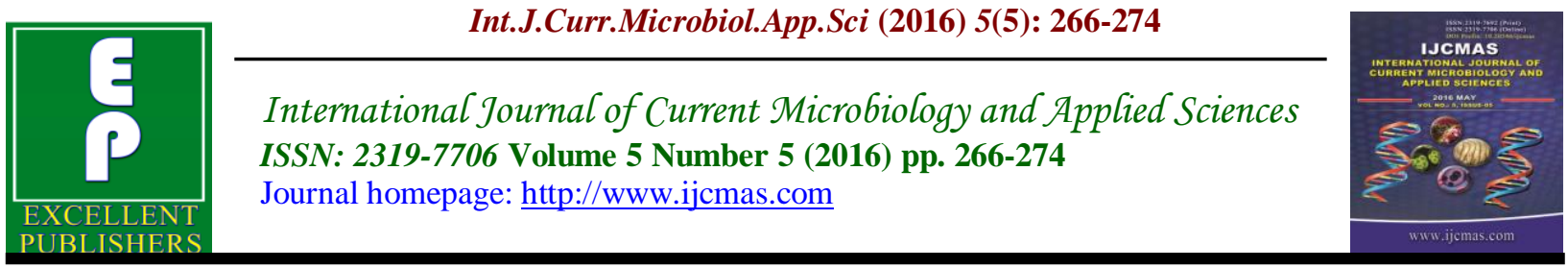

Original Research Article

http://dx.doi.org/10.20546/ijcmas.2016.505.029

\title{
Study of Hepatic Steatosis Index in Patients with Chronic HCV Infection
}

\author{
Nadia Elwan $^{1}$, Asem Elfert ${ }^{1}$, Sherief Abd-Elsalam ${ }^{1}$, Ayman Alska ${ }^{2}$, \\ Abdelrahman Kobtan ${ }^{1}$, Mohamed Yousef ${ }^{1}$, Samah Mosaad ${ }^{1}$, Osama Al-shourbgy ${ }^{1}$ \\ and Mohammed Elhendawy ${ }^{1}$ \\ ${ }^{1}$ Tropical Medicine and Infectious Diseases Department, Tanta University, Tanta, Egypt \\ ${ }^{2}$ Pathology Department, Tanta University, Tanta, Egypt \\ *Corresponding author
}

\begin{tabular}{|c|c|}
\hline & A B S T R A C T \\
\hline & $\begin{array}{l}\text { Hepatic steatosis is a frequent cause for elevated serum aminotransferase levels. } \\
\text { The main screening method is ultrasonography. A combination of non-invasive } \\
\text { tests may help in the diagnostic evaluation of a patient with suspected steatosis. }\end{array}$ \\
\hline $\begin{array}{l}\text { Ke y w o r d s } \\
\text { HCV, } \\
\text { Fibrosis, } \\
\text { Steatosis, } \\
\text { Hepatic } \\
\text { steatosis } \\
\text { index. }\end{array}$ & $\begin{array}{l}\text { Liver biopsy is the gold standard to precisely diagnose NASH. In this study we } \\
\text { assessed the usefulness of hepatic steatosis index in comparison with } \\
\text { ultrasonography and histopathological examination in the evaluation of steatosis } \\
\text { associated with HCV infection. This study was carried out at Tropical medicine } \\
\text { department (Tanta University Hospital). We studied fifty HCV patients who have } \\
\text { bright liver in ultrasound. All patients were further studied with histopathological } \\
\text { examination of liver biopsy as well as lab investigations. Hepatic steatosis index } \\
\text { was also calculated. A significant positive correlation has been found between }\end{array}$ \\
\hline Article Info & $\begin{array}{l}\text { hepatic steatosis index (HSI) and Metavir staging of fibrosis assessed by } \\
\text { histopathological examination. When the mean value of } \mathrm{HSI}=35.5 \text {, the stage was }\end{array}$ \\
\hline $\begin{array}{l}\text { Accepted: } \\
12 \text { April } 2016 \\
\text { Available Online: } \\
10 \text { May } 2016\end{array}$ & $\begin{array}{l}\text { F0 and when the mean value of HSI }=43.7 \text {, the stage was F3. A significant positive } \\
\text { correlation has also been found between hepatic steatosis index and } \\
\text { histopathological grading of steatosis. When the mean value of HSI }=31.7 \text {, the } \\
\text { grade was G0 and when the mean value of HSI }=39.1 \text {, the grade was G3. Hepatic } \\
\text { steatosis index may offer an economical noninvasive tool for predicting of hepatic } \\
\text { steatosis with reasonable accuracy. In practice, the index could be used for the } \\
\text { detection of risky patients in order to offer more advanced investigation, nutrition } \\
\text { and life style counselling, as well as for the detection of severe steatotic patients } \\
\text { requiring medical supervision and therapy. }\end{array}$ \\
\hline
\end{tabular}

\section{Introduction}

HCV infection is a major public health problem and silent killer. The World Health Organization estimates that hepatitis $\mathrm{C}$ virus (HCV) infection has a global prevalence of $3 \%$ or 200 million people (World Health
Organisation, 2006). Egypt is the worst affected with HCV infection, the overall prevalence positive $\mathrm{HCV}$ antibody was $14.7 \%$ (El-Zanaty et al., 2009) owing to the high transmission of $\mathrm{HCV}$ in the parenteral antischistosomal therapy campaign in the 1980s. 
Fatty liver, or hepatic steatosis, is a common finding in the general population and is a frequent cause for elevated serum aminotransferase levels (Angulo, 2002). This condition is considered to be the hepatic manifestation of the metabolic syndrome, where insulin resistance is the underlying factor with diabetes mellitus, obesity and hypertriglyceridaemia prominent clinical sequelae. Steatosis may occur with other assaults on the liver, particularly in alcohol abuse and also in chronic HCV infection.

$\mathrm{HCV}$ infection and hepatic steatosis are both independently common in the general population. Data estimating the prevalence of HCV infection and hepatic steatosis show that the frequency of chance concurrence would be $20 \%$ of $\mathrm{HCV}$-infected patients (Chan et al., 2009). Since the prevalence of hepatic steatosis in $\mathrm{HCV}$-infected patients is nearer to 50\% (Perz et al., 2004), the association is greater than one would expect to see from chance alone, suggesting an association between the two. Furthermore, hepatic steatosis is only seen in $18 \%$ of patients with hepatitis B infection (Thomopoulos et al., 2006).

The pathogenic association between $\mathrm{HCV}$ infection and hepatic steatosis is multifactorial. While hepatic steatosis in patients with HCV may be associated with features of the metabolic syndrome, socalled 'metabolic steatosis (Eckel et al., 2005) it may be present in the absence of these findings, often associated with genotype 3 infection: 'viral steatosis'

The main screening method is still classical ultrasonography, However, classical ultrasonography can only provide an approximate assessment of the degree of fatty liver infiltration. More over the use of this imaging modalities in mass screening of asymptomatic individuals are expensive (Lee et al., 2010).
A combination of simple available laboratory and imaging tests may help in the diagnostic evaluation of a patient with suspected NAFLD, liver biopsy remains the only reliable way to precisely diagnose NASH and establish the severity of liver injury and presence of fibrosis. It also provides important information regarding prognosis as well as response to therapeutic interventions.

But the prevalence of non-alcoholic fatty liver disease (NAFLD) is increasing in general population so it is impossible to perform liver biopsy in such a large number of patients to identify those with advanced fibrosis or non-alcoholic steatohepatitis. Liver biopsy has a potential sampling error; it is invasive and prone to complications, so it is no longer considered as mandatory as first line screening tools for chronic liver disease.

An equation that could predict the presence of hepatic steatosis depending on serum alanine aminotransferase (ALT) to serum aspartate aminotransferase (AST) plus body mass index (BMI), diabetes mellitus and gender was discussed.

Hepatic steatosis index $=8$ (ALT/AST) ratio + BMI (+2 if DM +2 if female).

So, the aim of this work was to study the usefulness of hepatic steatosis index in comparison with ultrasonography and histopathological examination in the evaluation of HCV infection.

\section{Patients and Methods}

After the approval of research ethics committee at Tanta Faculty of Medicine, this study was conducted in Tropical medicine department (Tanta University Hospital) during the period between November 2013 and April 2014. All known 
HCV patients coming to the department during this period were examined clinically and sonographically and patients who had bright liver by ultrasound were selected to be included in our study. Fifty known HCV patients were diagnosed to have hepatic steatosis. All of them gave an informed consent to share in the study.

The patients included in the study should have the following criteria: age 18 years or older, reactive anti $\mathrm{HCV}$ antibodies. Accepted hematological indices, compensated liver disease, serum creatinine should be within normal limits, diabetic patients should have their diabetes controlled, blood pressure should be in the range of (110-140 / 70-100 mm Hg).

Patients with any cause of chronic liver disease other than HCV infection, patients whose liver biopsy confirmed presence of cirrhosis, patients with active schistosomiasis, patients evidenced to have decompensated liver diseases (ascites or esophagealvarices ) and patients with poorly controlled diabetes were excluded from the study.

All patients were subjected to full history taking including personal history, special habits, e.g. smoking, alcohol, I.V. drug use, through clinical examination, past history of tartar emetic injection, blood transfusion, previous operations, dental procedures or contraceptive pills for females and history of hepatic diseases other than HCV.

Laboratory investigations were performed for all patients including Liver function tests (serum albumin, bilirubin (total \& differential), ALT, AST, ALP), coagulation profile: platelets count, prothrombin time \& activity and I.N.R, complete blood picture, renal function tests (blood urea and serum creatinine), blood glucose level, HCV antibodies and PCR, anthropometric parameters (weight and height).

Imaging evaluation including pelviabdominal ultrasonography to detect if there is liver brightness or not and grading as follow:

Grade 0- : Normal

Grade 1-: Slight diffuse increase in fine echoes in liver parenchyma with normal visualisation of the diaghragm and intahepatic vessel borders.

Grade 2-: Moderate diffuse increase in fine echoes with slightly impariedvisualisation of intahepatic vessels and the diaphragm.

Grade 3- : Marked increase in fine echoes with poor or no visualisation of intrahepatic vessel borders thediphragm and the posterior right lobe of the liver.

Liver biopsy was done for histopathological study. The liver biopsy is usually performed on an outpatient basis. A mild sedative was given to the patient prior to the procedure, an ultrasound was used to identify the best location to make the biopsy. The patient lied quietly on the back or slightly to the left side. That area of the skin where the biopsy was done was carefully cleaned. Then, a local anesthetic agent was used to numb the skin and tissue below. A disposable biopsy thin needle was inserted through the skin. At this point, the patient was told how to breathe. The needle was advanced into and out of the liver. This took only 1 or 2 seconds. A slender core of tissue was removed with the needle, and was then processed through the laboratory. The entire procedure from start to finish lasted only 15 to 20 minutes.

For recovery, the patient was kept at rest for several hours following The Procedure. We checked the heart rate and blood pressure during this time. There was may be some discomfort in the chest or shoulder, however, this was usually temporary. 
Medication was available for this discomfort, if needed. Before being discharged, the patient was given instructions about returning to normal activities and about eating. Activity was usually restricted for a day or so after the biopsy. However, the procedure did not require a long recovery period.

For histopathology, routine $\mathrm{H} \& \mathrm{E}$ Histopathological sections were prepared \& special stains if needed and grading as follows:

Grade 0: None

Grade 1: Up to $33 \%$

Grade 2: $33 \%-66 \%$

Grade 3 :> 66\%

Hepatic steatosis index was done for all patients.

Hepatic steatosis index $=8$ (ALT/AST) ratio $+\mathrm{BMI}(+2$ if $\mathrm{DM}+2$ if female $)$.

\section{Results and Discussion}

Forty of our patients were males $(80 \%)$ and 10 were females $(20 \%)$. Eighteen percent of our patients were diabetics and $82 \%$ were not diabetic.

Liver brightness was assessed by ultrasonography in all patients. grade 0 $(2 \%)$, grade $1(42 \%)$, grade $2(38 \%)$ and grade3 (18\%) . Hepatic steatosis was assessed also by histopathological examination. grade $0(6 \%)$, grade $1(28 \%)$, grade $2(40 \%)$ and grade $3(26 \%)$ (Table 1$)$.

A significant positive correlation was found between histopathological grading of steatosis and ultrasonographic grading of steatosis (Table 2).

A significant positive correlation has been found between Metavir stage of fibrosis and ultrasonographic grading of steatosis (Table $3)$.

A significant correlation has been found between histopathological grading of steatosis and Metavir stage of fibrosis (Table 4).

A significant positive correlation has been found between hepatic steatosis index and Metavir staging of fibrosis assesed by histopathological examination. When the mean value of HSI $=35.450 \pm 3.930$ the stage was F0 and when the mean Value of HSI $=43.650 \pm 0.495$ the stage was F3 (Table 5).

A significant positive correlation has been found between hepatic steatosis index and Ultrasound grading of steatosis. When the mean value of HSI $=31.700+2.663$ the grade was G0 and when the mean Value of $\mathrm{HSI}=39.037+4.541$ the grade was G3 (Table 6).

In our study, fifty patients with $\mathrm{CHC}$ infection were examined clinically, had laboratory investigations, examined by abdominal ultrasonography, and histopathological examination of a true cut liver biopsy.

The main screening method of steatosis is still classical ultrasonography, a widely spread, accessible, fast method with good diagnostic performance sensitivity $67 \%$, specificity $77 \%$ and the overall accuracy was75\% (Sporea et al., 2009).

In our study, we have found that most of our patients have mild to moderate steatosisassesed by ultrasonography: grade 0 (2\%), grade $1(42 \%)$, grade $2(38 \%)$ and grade $3(18 \%)$. This meets the results of $\mathrm{Hu}$ et al., who found that most of patients with $\mathrm{HCV}$ infection have mild to moderate steatosis. 
Several studies have examined the ability of ultrasound in recognizing fatty liver among patients suspected of having liver disease, using liver biopsy as the comparison standard, and reported sensitivity values between 60 and $94 \%$ and specificity values between 84 and $95 \%$. This was in harmony with our results where we found asignificant positive correlation between ultrasound grading of hepatic steatosis and histopathological grading of steatosis. This means that ultrasound is a diagnostic tool for hepatic steatosis to some extent and this meets the results of Sporea et al., 2009.

However, classical ultrasonography can only provide an approximate assessment of the degree of fatty liver infiltration. There is limitation of radiological modalities in the study of hepatic steaosis where only steatosis $>25-30 \%$ could be reliably detected radiologically.

Table.1 Grading of Hepatic Steatosis Assesed by Ultrasound and by Histopathology

\begin{tabular}{|l|l|l|l|l|l|l|l|l|}
\hline \multicolumn{4}{|l|}{ U/S } & \multicolumn{3}{l|}{ Histopathology } & \multicolumn{2}{l|}{ Fibrosis } \\
\hline & N & $\%$ & & N & $\%$ & & N & $\%$ \\
\hline G0 & 1 & 2.00 & G0 & 3 & 6.00 & F0 & 16 & 32.00 \\
\hline G1 & 21 & 42.00 & G1 & 14 & 28.00 & F1 & 25 & 50.00 \\
\hline G2 & 19 & 38.00 & G2 & 20 & 40.00 & F2 & 7 & 14.00 \\
\hline G3 & 9 & 18.00 & G3 & 13 & 26.00 & F3 & 2 & 4.00 \\
\hline Total & 50 & 100.00 & Total & 50 & 100.00 & Total & 50 & 100.00 \\
\hline
\end{tabular}

Table.2 Correlation between Histopathological Grading of Steatosis and Ultrasonographic Grading of Steatosis

\begin{tabular}{|c|c|c|c|c|c|c|}
\hline \multirow{2}{*}{\multicolumn{2}{|c|}{ Histopath }} & \multicolumn{5}{|l|}{$\mathrm{U} / \mathrm{S}$} \\
\hline & & \multirow{2}{*}{$\begin{array}{l}\text { G0 } \\
1\end{array}$} & \multirow{2}{*}{$\begin{array}{l}\text { G1 } \\
2\end{array}$} & \multirow{2}{*}{$\begin{array}{l}\mathrm{G} 2 \\
0\end{array}$} & \multirow{2}{*}{$\begin{array}{ll}\text { G3 } \\
0\end{array}$} & \multirow{2}{*}{$\begin{array}{l}\text { Total } \\
3\end{array}$} \\
\hline \multirow{2}{*}{ G0 } & $\bar{N}$ & & & & & \\
\hline & $\%$ & 100.00 & 9.52 & 0.00 & 0.00 & 6.00 \\
\hline \multirow{2}{*}{ G1 } & $\mathrm{N}$ & 0 & 11 & 3 & 0 & 14 \\
\hline & $\%$ & 0.00 & 52.38 & 15.79 & 0.00 & 28.00 \\
\hline \multirow{2}{*}{ G2 } & $\mathrm{N}$ & 0 & 8 & 9 & 3 & 20 \\
\hline & $\%$ & 0.00 & 38.10 & 47.37 & 33.33 & 40.00 \\
\hline \multirow{2}{*}{ G3 } & $\mathrm{N}$ & 0 & 0 & 7 & 6 & 13 \\
\hline & $\%$ & 0.00 & 0.00 & 36.84 & 66.67 & 26.00 \\
\hline \multirow{2}{*}{ Total } & $\mathrm{N}$ & 1 & 21 & 19 & 9 & 50 \\
\hline & $\%$ & 100.00 & 100.00 & 100.00 & 100.00 & 100.00 \\
\hline & $\mathrm{X} 2$ & \multicolumn{5}{|l|}{35.165} \\
\hline 光 & $\begin{array}{l}\mathrm{P}- \\
\text { value }\end{array}$ & \multicolumn{5}{|c|}{$<0.001 * *$} \\
\hline
\end{tabular}


Table.3 Correlation between Metavir Stage of Fibrosis and Ultrasonographic Grading of Steatosis

\begin{tabular}{|c|c|c|c|c|c|c|}
\hline \multirow{2}{*}{\multicolumn{2}{|c|}{ Fibrosis }} & \multicolumn{5}{|l|}{$\mathrm{U} / \mathrm{S}$} \\
\hline & & \multirow{2}{*}{$\begin{array}{l}\text { G0 } \\
1\end{array}$} & \multirow{2}{*}{$\begin{array}{l}\text { G1 } \\
11\end{array}$} & \multirow{2}{*}{$\begin{array}{l}\mathrm{G} 2 \\
4\end{array}$} & \multirow{2}{*}{$\begin{array}{l}\text { G3 } \\
0\end{array}$} & \multirow{2}{*}{$\begin{array}{l}\text { Total } \\
16\end{array}$} \\
\hline 5 & $\mathrm{~N}$ & & & & & \\
\hline $\mathrm{FO}$ & $\%$ & 100.00 & 52.38 & 21.05 & 0.00 & 32.00 \\
\hline \multirow{2}{*}{$\mathrm{F} 1$} & $\mathrm{~N}$ & 0 & 9 & 12 & 4 & 25 \\
\hline & $\%$ & 0.00 & 42.86 & 63.16 & 44.44 & 50.00 \\
\hline \multirow{2}{*}{$\mathrm{F} 2$} & $\mathrm{~N}$ & 0 & 1 & 2 & 4 & 7 \\
\hline & $\%$ & 0.00 & 4.76 & 10.53 & 44.44 & 14.00 \\
\hline \multirow{2}{*}{ F3 } & $\mathrm{N}$ & 0 & 0 & 1 & 1 & 2 \\
\hline & $\%$ & 0.00 & 0.00 & 5.26 & 11.11 & 4.00 \\
\hline \multirow{2}{*}{ Total } & $\mathrm{N}$ & 1 & 21 & 19 & 9 & 50 \\
\hline & $\%$ & 100.00 & 100.00 & 100.00 & 100.00 & 100.00 \\
\hline \multirow{2}{*}{$\begin{array}{l}\text { Chi- } \\
\text { Square }\end{array}$} & $\mathrm{X} 2$ & \multicolumn{5}{|l|}{20.197} \\
\hline & $\begin{array}{l}\mathrm{P}- \\
\text { value }\end{array}$ & \multicolumn{5}{|l|}{$0.017^{*}$} \\
\hline
\end{tabular}

Table.4 Correlation between Histopathological Grading of Steatosis and Metavir Staging of Fibrosis

\begin{tabular}{|c|c|c|c|c|c|c|}
\hline \multirow{2}{*}{\multicolumn{2}{|c|}{ Fibrosis }} & \multicolumn{5}{|c|}{ Histopathology } \\
\hline & & \multirow{2}{*}{$\begin{array}{l}\text { G0 } \\
3\end{array}$} & \multirow{2}{*}{$\begin{array}{l}\text { G1 } \\
8\end{array}$} & \multirow{2}{*}{$\begin{array}{l}\mathrm{G} 2 \\
3\end{array}$} & \multirow{2}{*}{$\begin{array}{l}\text { G3 } \\
2\end{array}$} & \multirow{2}{*}{$\begin{array}{l}\text { Total } \\
16\end{array}$} \\
\hline 50 & $\mathrm{~N}$ & & & & & \\
\hline & $\%$ & 100.00 & 57.14 & 15.00 & 15.38 & 32.00 \\
\hline \multirow{2}{*}{$\mathrm{F} 1$} & $\mathrm{~N}$ & 0 & 5 & 15 & 5 & 25 \\
\hline & $\%$ & 0.00 & 35.71 & 75.00 & 38.46 & 50.00 \\
\hline \multirow{2}{*}{$\mathrm{F} 2$} & $\mathrm{~N}$ & 0 & 1 & 2 & 4 & 7 \\
\hline & $\%$ & 0.00 & 7.14 & 10.00 & 30.77 & 14.00 \\
\hline \multirow{2}{*}{ F3 } & $\mathrm{N}$ & 0 & 0 & 0 & 2 & 2 \\
\hline & $\%$ & 0.00 & 0.00 & 0.00 & 15.38 & 4.00 \\
\hline \multirow{2}{*}{ Total } & $\mathrm{N}$ & 3 & 14 & 20 & 13 & 50 \\
\hline & $\%$ & 100.00 & 100.00 & 100.00 & 100.00 & 100.00 \\
\hline & $\mathrm{X} 2$ & \multicolumn{5}{|l|}{23.810} \\
\hline 当 & $\begin{array}{l}\mathrm{P}- \\
\text { value }\end{array}$ & \multicolumn{5}{|l|}{$0.005 *$} \\
\hline
\end{tabular}


Table.5 Correlation between HSI and Staging of Fibrosis

\begin{tabular}{|c|c|c|c|c|c|c|c|}
\hline$\infty$ & HIS & & & & & ANO & \\
\hline 泀 & Range & & Mean & \pm & SD & $\mathrm{F}$ & P-value \\
\hline F0 & 29.200 & -42.600 & 35.450 & \pm & 3.930 & \multirow{4}{*}{2.922} & \multirow{4}{*}{$0.044^{*}$} \\
\hline F1 & 32.300 & - 47.500 & 37.218 & \pm & 3.955 & & \\
\hline $\mathrm{F} 2$ & 32.600 & - 40.900 & 37.014 & \pm & 3.187 & & \\
\hline F3 & 43.300 & -44.000 & 43.650 & \pm & 0.495 & & \\
\hline
\end{tabular}

Table.6 Correlation between HSI and Ultrasonographic Grading of Steatosis

\begin{tabular}{|c|c|c|c|c|c|c|c|}
\hline \multirow[b]{2}{*}{ US } & \multicolumn{5}{|l|}{ HIS } & \multicolumn{2}{|c|}{ ANOVA } \\
\hline & Range & & Mean & \pm & SD & $\mathrm{F}$ & $\begin{array}{l}\text { P- } \\
\text { value }\end{array}$ \\
\hline G0 & 29.200 & - $\quad 34.500$ & 31.700 & \pm & 2.663 & \multirow{4}{*}{4.543} & \multirow{4}{*}{$0.007 *$} \\
\hline G1 & 31.700 & - $\quad 38.900$ & 35.279 & \pm & 2.580 & & \\
\hline G2 & 32.100 & - 44.900 & 37.378 & \pm & 3.739 & & \\
\hline G3 & 32.600 & - 47.500 & 39.037 & \pm & 4.541 & & \\
\hline
\end{tabular}

In our patients, the degree of steatosis assessed by histopathological examination. Were grade $0(6 \%)$, grade $1(28 \%)$, grade $2(40 \%)$ and grade $3(26 \%)$. So we found that most of them (68\%) had mild to moderate steatosis grade $1(28 \%)$, grade $2(40 \%)$. This meets the results of $\mathrm{Hu}$ et al., 2007.

In our study, most of our patients had mild grade of fibrosis assessed by histopathological examination (32\%) F0, $(50 \%)$ were F1. A significant positive correlation hasbeen found between Metavir stage of fibrosis and steatosis assessed by both ultrasound and histopathological examination, this means that there is link between steatosis and fibrosis and patients with steatosis and $\mathrm{HCV}$ infection were found to be at risk of accelerated fibrosis. This meets the results of Westin et al., 2002 who found significant relation between steatosis and the extent of fibrosis. Leandro et al., 2006 believed that hepatic steatosis is an important and independent risk factor for developing hepatic fibrosis in CHC infection. However, a study performed by Preumalswami et al., 2006 suggested that hepatic steatosis was not related to hepatic fibrosis in $\mathrm{CHC}$ infection.

Hwang et al., 2001 have pointed out that the stage of hepatic fibrosis is generally advanced in patients with hepatic steatosis compared to those without steatosis. 
An equation that could predict the presence of hepatic steatosis depending on serum alanine aminotransferase (ALT) to serum aspartate aminotransferase (AST) plus body mass index (BMI), diabetes mellitus and gender was discussed.

Hepatic steatosis index $=8(\mathrm{ALT} / \mathrm{AST})$ ratio + BMI $(+2$ if $\mathrm{DM}+2$ if female).

In our study, Hepatic steatosis index applicated on fifty $\mathrm{CHC}$ infected known steatotic patients assessed by ultrasound. A significant positive correlation has been found between hepatic steatosis index and Ultrasound grading of steatosis. With increase in the hepatic steatosis index there is increase in the grading of steatosis assessed by ultrasound. When the mean value of $\mathrm{HSI}=31.700+2.663$ the grade was G0 and when the mean value of HSI = $39.037+4.541$ the grade was G3 this meets the results of JH-Lee et al ., 2010.

A significant positive correlation has been found between hepatic steatosis index and Metavir staging of fibrosis assessed by histopathological examination. Withincrease in the hepatic steatosis index there is increase in the staging of fibrosis. When the mean value of HSI $=35.450+3.930$ the stage was F0 and when the mean Value of $\mathrm{HSI}=43.650+0.495$ the stage was F3. We found that hepatic steatosis index is a good, simple, non invasive, cheap, accessible, and fast method for predicting hepaticsteatosis. This was agreed with Lee et al., 2010 who found that this index was useful in diagnosis of fatty liver in comparison with ultrasound .

So, the derived index may offer an economical non invasive means for predicting of NAFLD with reasonable accuracy. In practice, the index could be used for the detection of risky patients in order to offer more advanced investigation, nutrition and life style counselling, as well as for the detection of severe steatotic patients requiring medical supervision and therapy.

Ethical approval: The study protocol was approved by the ethical committee of faculty of medicine, Tanta University. Informed consent was obtained from each patient before participation in the study.

\section{References}

World Health Organisation. 2006. Hepatitis C - Global Surveillance Update. Weekly Epidemiological Record, 75: 17-28.

El-Zanaty, F., Way, A. 2009. Egypt Demographic and Health Survey 2008. Egyptian: Ministry of Health. Cairo: El-Zanaty and Associates, and Macro International.

Angulo, P. 2002. Nonalcoholic fatty liver disease. N. Engl. J. Med., 346: 12211231.

Chan, H., Wong, G., Choi, P., et al. 2009. Alanine aminotransferase-based algorithms of liver stiffness measurement by transient elastography (Fibroscan) for liver fibrosis in chronic hepatitis B. J. Viral Hepat., 1: 36-44.

Perz, J., Farrington, L., Pecoroco, C., et al. 2004. Estimated Global Prevalence of Hepatitis C. 42nd Annual Meeting of Infectious Diseases society of America, Boston, MA, USA.

Thomopoulos, K., Arvaniti, V., Tsamantas, A., et al. 2006. Prevalence of liver steatosis in patients with chronic hepatitis B: a study of associated factors and relationship with fibrosis. Eur. J. Gastroenterol. Hepatol., 18: 233-237.

Eckel, R., Grundy, S., Zimmet, P., et al. 2005. The metabolic syndrome. Lancet, 365: 1415-1428. 
Lee, J.H., Park, S., Kim, K., et al. 2010. Hepatic steatosis index : a simple screening tool reflecting NAFLD. Digestive and liver dis., 42: 503-508.

Saadeh, S., Younossi, Z., Remer, E., et al. 2002. The utility of radiological imaging in nonalcoholic fatty liver disease. Gastroenterol., 123: 745-750.

Sporea, I., Şirli, R., Başa, E., et al. 2009. The value of transabdominal ultrasound for assessment of the severity of liver steatosis as compared to liver biopsy. Central European J. Med., 4: 490-495.

Hu, K.Q., Currie, S.L., Shen, H., et al. 2007. Clinical implications of hepatic steatosis in patients with chronic hepatitis C: a multicenter study of U.S. veterans. Dig. Dis. Sci., 52(2): 570-8.

Joy, D., Thava, V., Scott, B., et al. 2003. Diagnosis of fatty liver disease: is biopsy necessary? Eur. J. Gastroenterol. Hepatol., Vol.15, No.5, pp. 539-43.

Westin, J., Nordlinder, H., Lagging, M.. et al. 2002. Steatosis accelerates fibrosis development over time in hepatitis $\mathrm{C}$ virus genotype 3 infected patients. $J$ Hepatol., 37: 837-842.

Leandro, G., Mangia, A., Hui, J., et al. 2006. Relationship between steatosis, inflammation, and fibrosis in chronic hepatitis $\mathrm{C}$ : a meta-analysis of individual patient data. Gastroenterol., 130: 1636-1642.

Perumalswami, P., Kleiner, D.E., Lutchman, G., et al. 2006. Steatosis and progression of fibrosis in untreated patients with chronic hepatitis C infection. Hepatol., 43(4): 780-7.

Hwang, S., Luo, J., Chu, C., et al. 2001. Hepatic steatosis in chronic hepatitis $\mathrm{C}$ virus infection: prevalence and clinical correlation. J. Gastroenterol. Hepatol., 16: $190-195$.

\section{How to cite this article:}

Nadia Elwan, Asem Elfert, Sherief Abd-Elsalam, Ayman Alska, Abdelrahman Kobtan, Mohamed Yousef, Samah Mosaad, Osama Al-shourbgy and Mohammed Elhendawy. 2016. Study of Hepatic Steatosis Index in Patients with Chronic HCV Infection. Int.J.Curr.Microbiol.App.Sci. 5(5): 266-274. doi: http://dx.doi.org/10.20546/ijcmas.2016.505.029 